Dossiê Especial: Experiências do PIBID na formação inicial e continuada de professores de

línguas estrangeiras

HIBARINO \& NODARI (orgs)

Revista X, vol.1, 2015

\title{
AS CONCEPÇÕES FORMATIVAS E AS PRESCRIÇÕES AO TRABALHO DOCENTE TEXTUALIZADAS NO REGULAMENTO DO PIBID
}

The educational conceptions and the prescriptions to the teachers' work textualized in the PIBID's Regulation

\author{
Priscila Azevedo da Fonseca LANFERDINI ${ }^{1}$
}

\begin{abstract}
Resumo: O crescente aumento de projetos e programas de formação docente, propostos no âmbito das políticas públicas brasileiras, acarreta a necessidade de pesquisas que busquem compreender as possibilidades e limitações de tais iniciativas. Deste modo, neste artigo objetivamos analisar o Regulamento do Programa Institucional de Bolsa de Iniciação à Docência (PIBID), a fim de investigar que concepção(ões) formativa(s) e que prescrições ao trabalho docente são textualizadas no documento. Para a análise do regulamento utilizamos o modelo de análise de textos de Bronckart (1999); Bronckart e Machado (2004); Machado e Bronckart (2009), no que se refere a três níveis procedimentais de análise: organizacional, enunciativo e semântico. Os resultados apontaram que o programa alinha-se às propostas contemporâneas de formação. As prescrições dadas ao trabalho dos professores participantes compreendem diferentes aspectos do trabalho docente, estendendo-se do planejamento à avaliação das atividades desenvolvidas. As prescrições voltadas ao trabalho dos alunos-bolsistas é genérica e depende das atividades propostas nos projetos e subprojetos.
\end{abstract}

Palavras-chave: políticas públicas; Regulamento do PIBID; formação docente; trabalho prescrito.

\begin{abstract}
The increasing number of teacher education projects and programs, offered in the Brazilian public policies scope, lead to the need of researches that attempt to understand the possibilities and limitations of such initiatives. Given this context, in this article, we aim at analyzing the Institutional Program Scholarship for Teacher Initiation (PIBID) Regulation, in order to investigate which education conception(s) and prescriptions to the teachers' work are textualized in the document. For the analysis, we used the analysis model of texts proposed by Bronckart (1999); Bronckart and Machado (2004); Machado and Bronckart (2009) in three procedural levels: organizational, enunciative and semantic. The results indicated that the program is aligned to the contemporary educational proposals. The work prescribed to the teachers involves different aspects of teaching, extending from planning to evaluation of the developed activities. The work prescribed to the novice teachers is generic and depends on the activities proposed in the projects and subprojects.
\end{abstract}

Keywords: public policies; PIBID Regulation; teachers' education; prescribed work.

\footnotetext{
${ }^{1}$ Professora da rede pública de ensino do Estado do Paraná. Professora. supervisora do PIBID Letras-Inglês (UNICENTRO). Doutoranda do Programa de Pós-Graduação em Estudos da Linguagem da Universidade Estadual de Londrina (PPGEL-UEL), orientada pela Profa. Dra. Vera Lúcia Lopes Cristóvão (UEL).
} 


\section{Dossiê Especial: Experiências do PIBID na formação inicial e continuada de professores de \\ línguas estrangeiras \\ HIBARINO \& NODARI (orgs) \\ Revista X, vol.1, 2015}

\section{Introdução}

Nos últimos anos no Brasil estamos vivenciando o crescimento de projetos e programas no âmbito das políticas públicas voltados à formação inicial e continuada de professores (PIBID, $\mathrm{PDE}^{2}$, Programa Novos Talentos ${ }^{3}$, Prodocência ${ }^{4}$, entre outros). As implementações recentes de tais iniciativas as revelam como instâncias carentes de pesquisa, uma vez que se evidencia a necessidade de compreender a natureza e a abrangência de tais propostas governamentais. A inserção de uma diversidade de projetos e programas estaduais e federais no contexto educacional; confirma que; a formação docente tem sido vista como área decisiva na mediação das transformações sociais demandadas pela sociedade.

Diante desse contexto, esse artigo visa investigar uma dessas iniciativas, mais especificamente temos como objetivo principal apresentar uma análise do Regulamento do Programa Institucional de Bolsa de Iniciação à Docência - PIBID (2013) ${ }^{5}$, a fim de identificar que concepção(es) formativa(s) e que prescrições ao trabalho docente são textualizadas no documento. Pretendemos analisar o regulamento a fim de responder as seguintes perguntas: a) que concepção(ões) formativa(s) norteiam o PIBID? b) quem são os protagonistas no regulamento do programa? c) qual o trabalho prescrito aos participantes do programa?

Nosso interesse em responder tais perguntas se deve ao fato de que o programa PIBID foi recentemente institucionalizado enquanto política pública. Deste modo, ele vem se constituindo como um novo espaço de formação docente, cujo objetivo central é estreitar os laços entre a escola pública e a universidade, promovendo a inserção de alunos-professores no contexto escolar desde o início de sua formação, bem como a interação de professores da rede básica de ensino, alunos licenciandos e professores da educação superior. Defendemos, assim, a relevância da análise de seu regulamento, uma vez que ele norteia a elaboração dos editais de seleção, dos projetos e, consequentemente, dos subprojetos do programa com suas

\footnotetext{
${ }^{2}$ O PDE (Programa de Desenvolvimento Educacional) é um programa de formação continuada oferecido pela Secretaria de Estado da Educação do Estado do Paraná (SEED), desde o ano de 2007. Informações sobre o PDE podem ser encontradas no site: http://www.gestaoescolar.diaadia.pr.gov.br/modules/conteudo/conteudo.php?conteudo=20

${ }^{3}$ O Programa Novos Talentos (Programa de Apoio a Projetos Extracurriculares: investindo em novos talentos da rede de educação pública para inclusão social e desenvolvimento da cultura científica) oferece atividades extracurriculares para alunos e professores das escolas públicas, financiadas pela CAPES. Informações sobre o Programa Novos Talentos podem ser encontradas no site: http://www.capes.gov.br/educacao-basica/novostalentos

${ }^{4}$ O Prodocência (Programa de Consolidação das Licenciaturas) é um programa de formação inicial financiado pela CAPES. Informações sobre o programa podem ser encontradas no site: http://www.capes.gov.br/educacaobasica/prodocencia

${ }_{5}$ O programa PIBID; é um programa de formação inicial e continuada de professores financiado pela Coordenação de Aperfeiçoamento de Pessoal de Nível Superior (CAPES).
} 
Dossiê Especial: Experiências do PIBID na formação inicial e continuada de professores de

línguas estrangeiras

HIBARINO \& NODARI (orgs)

Revista X, vol.1, 2015

propostas relativas à formação inicial e continuada de professores das universidades participantes de todo o país. Assim, tal regulamento se configura como um documento prescritivo do trabalho do professor formador ${ }^{6}$ e dos alunos bolsistas na educação básica.

Para a análise do documento nos ancoramos nos aportes teórico-metodológicos do interacionismo sociodiscursivo (ISD), mais especificamente utilizamos o modelo de análise de texto de Bronckart (1999); Bronckart e Machado (2004); Machado e Bronckart (2009), como melhor detalhado na seção que segue.

\section{O quadro teórico-metodológico escolhido para a análise do regulamento}

Diante do interesse de compreender como as atividades de trabalho, dentre elas a do trabalho educacional, são construídas e/ou compreendidas em textos orais e escritos sobre/no/como trabalho, textos prescritivos do trabalho do professor têm sido foco de vários estudos filiados à corrente teórica do ISD (MACHADO; CRISTOVÃO, 2009; LEITE, 2009; REGISTRO; STUTZ, 2008; MACHADO; BRONCKART, 2005; BRONCKART; MACHADO, 2004). Considerando os resultados obtidos por estes estudos e os objetivos de nosso artigo, acreditamos que o ISD nos oferece relevantes recursos teórico-metodológicos para a análise do Regulamento do PIBID, dada a sua proposta metodológica para a análise de textos e sua concepção ampliada do trabalho docente para além dos limites da sala de aula (BRONCKART; MACHADO, 2004).

Em busca de uma melhor compreensão da textualização da realidade do trabalho, o ISD tem se servido de conceitos teóricos e procedimentos metodológicos da ergonomia da atividade (AMIGUES, 2004; SAUJAT, 2004); e da psicologia do trabalho (CLOT, 2006; FAITA, 2004). Dentre eles, o ISD utiliza-se de três conceitos importantes para nossas análises: "trabalho prescrito", "trabalho real" e "trabalho realizado". As definições de tais conceitos pressupõem a existência de uma distância entre o que é prescrito e o trabalho da forma como é efetivamente realizado.

O trabalho prescrito é comumente materializado nos chamados textos prescritivos. $\mathrm{Na}$ área educacional são exemplos de textos prescritivos ${ }^{7}$ : os planos de aula, programa de

\footnotetext{
${ }^{6}$ O programa do PIBID considera os professores da educação básica como corresponsáveis pela formação dos licenciando participantes do programa, sendo desta maneira professores formadores.

${ }^{7}$ Alguns autores utilizam o termo "textos prefigurativos" para se referir a documentos como os PCN, as DCE, etc; entendendo que estes textos orientam o trabalho docente sem recorrer às formulações convencionais de uma prescrição (BUENO, 2007). Para este artigo utilizamos do termo "textos prescritivos" para se referir a estes documentos e a outros textos que apresentem "prescrições" ao trabalho, nos baseamos para tanto nos estudos de
} 
Dossiê Especial: Experiências do PIBID na formação inicial e continuada de professores de

línguas estrangeiras

HIBARINO \& NODARI (orgs)

Revista X, vol.1, 2015

curso, material didático, os PCN (Parâmetros Curriculares Nacionais, 1998), as DCE (Diretrizes Curriculares do Estado do Paraná, 2006), o PPP (Projeto Político Pedagógico), o próprio Regulamento do PIBID, entre outros. O trabalho prescrito está relacionado ao conceito de tarefa, correspondendo à prescrição do que deve ser feito pelo trabalhador. $\mathrm{O}$ trabalho real relaciona-se ao conceito de atividade, correspondendo ao trabalho mental realizado pelo sujeito na realização do trabalho, não sendo possível, assim, a sua observação concreta (AMIGUES, 2004). O trabalho real compreende tudo aquilo que o sujeito faz, deixa de fazer, é impedido de fazer, ou gostaria de ter feito. Já o "trabalho realizado"; compreende as ações realmente realizadas pelo indivíduo em situação de trabalho.

Para análise de textos produzidos em situação de trabalho, sobre o trabalho e de texto prescritivos do trabalho, Bronckart e Machado (2004) e Machado e Bronckart (2009) reorganizam a proposta de análise de textos de Bronckart (1999) e; propõem uma análise que prevê três níveis procedimentais pertencentes às análises textual/discursiva: nível organizacional, nível enunciativo e nível semântico. Assim como proposto por Bronckart (1999), o modelo de análise de textos é baseado em uma perspectiva descendente, ou seja, a análise de textos parte primeiramente do contexto sócio-histórico mais amplo das ações de linguagem para os textos, e por fim às análises de sua arquitetura interna. Na sequência procuramos expor brevemente o modelo ${ }^{8}$.

Primeiramente, realiza-se o levantamento do contexto de produção dos textos, ou seja, das suas condições de produção, que envolve o momento sócio-histórico mais amplo em que o texto foi produzido, seu emissor e receptor, seus papéis sociais, os objetivos de comunicação, o suporte de veiculação, textos com os quais estabelece relações intertextuais, etc. (MACHADO; BRONCKART, 2009).

No nível organizacional, faz-se a identificação do plano global do texto, ou seja, da organização do conteúdo temático. Realiza-se ainda, a análise dos tipos de discurso, que são formas linguísticas identificáveis no texto baseadas na descrição dos mundos (mundo ordinário e discursivo) e das sequências que se referem à organização sequencial ou linear do conteúdo temático no texto, sendo elas: narrativa, descritiva, argumentativa, explicativa,

Machado e Cristovão (2009); Machado; Lousada; Baradi; Tardelli; Tognato (2009) e Machado e Bronckart (2005).

${ }^{8}$ Os procedimentos utilizados para identificação das unidades de análise do modelo de análise de texto do ISD são os mesmo já explicitados por Bronckart (1999) e demais pesquisadores que assumem esse referencial teórico; por essa razão, priorizaremos nesse artigo a descrição das unidades utilizadas em nossas análises. Para uma descrição mais detalhada das demais unidades (tipos de discurso, tipos de sequência, marcas de pessoas, etc) propostas por este quadro teórico, ver Machado e Bronckart (2009); Bronckart e Machado (2004) e Bronckart (1999). 


\section{Dossiê Especial: Experiências do PIBID na formação inicial e continuada de professores de línguas estrangeiras \\ HIBARINO \& NODARI (orgs) \\ Revista X, vol.1, 2015}

injuntiva e dialogal. No nível enunciativo, as análises voltam-se à verificação dos mecanismos de responsabilização enunciativa, englobando as marcas de pessoa, marcas de inserção de vozes, ocorrência ou não de modalizadores do enunciado.

Bronckart (1999) define as vozes como "entidades que assumem (ou às quais são atribuídas) a responsabilidade do que é enunciado" (BRONCKART, 1999, p. 326). De acordo com o autor, na maioria das vezes, a responsabilidade pelo que é dito é assumida diretamente pela instância geral de comunicação. Essa voz que geralmente é do narrador ou do expositor, é denomina de voz neutra (BRONCKART, 1999). No entanto, existem alguns casos em que a instância de enunciação atribui a responsabilidade do dizer a outras vozes, que são denominadas pelo autor como vozes secundárias. Bronckart propõe três categorias gerais para as vozes secundárias: vozes de personagem, vozes sociais e voz do autor. As vozes de personagens são vozes atribuídas a seres humanos ou entidades humanizadas (como animais nos contos), quando assumem o papel de agentes ${ }^{9}$ nos acontecimentos ou nas ações que constituem o conteúdo temático. As vozes sociais são vozes provenientes de personagens, grupos ou instituições sociais, aos quais não são atribuídos o papel de agentes dos acontecimentos ou ações mobilizadas no percurso temático, mas são consideradas como instâncias externas de avaliação de alguns aspectos do conteúdo. A voz do autor, por sua vez, é a voz proveniente do autor do texto, que pode intervir na avaliação ou tecer comentários sobre alguns aspectos do que é dito.

As modalizações podem ser definidas como unidades linguísticas, utilizadas para expressar avaliações e/ou julgamentos a respeito dos conteúdos temáticos mobilizados no texto. De acordo com Bronckart (1999), as modalizações apresentam quatro funções: lógica, deôntica, apreciativa e pragmática.

As modalizações lógicas são utilizadas para expressar avaliações de elementos do conteúdo temático no quadro das coordenadas do mundo objetivo. Elas apresentam os elementos do conteúdo temático enquanto condições de verdade, fatos atestados, certos, possíveis, prováveis, eventuais, necessários, etc. As modalizações deônticas são usadas para expressar avaliações de alguns elementos do conteúdo temático baseadas em valores, opiniões e regras do mundo social. No uso destas modalizações os elementos do conteúdo temático são apresentados como sendo do domínio dos direitos, das obrigações sociais, da conformidade às

\footnotetext{
${ }^{9} \mathrm{O}$ quadro teórico do ISD distingue os termos actante, ator e agente. O termo actante é utilizado para se referir a qualquer pessoa implicada no agir; o termo ator é utilizado quando o actante é colocado como fonte de um processo, sendo-lhe atribuídas capacidades, motivos e intenções para o agir; Já o termo agente é usado quando não são atribuídas ao actante as propriedades de ator. (Bronckart; Machado, 2004).
} 
Dossiê Especial: Experiências do PIBID na formação inicial e continuada de professores de línguas estrangeiras

HIBARINO \& NODARI (orgs)

Revista X, vol.1, 2015

normas estabelecidas socialmente. As modalizações apreciativas são utilizadas nas expressões de avaliações de alguns aspectos do conteúdo temático no quadro das coordenadas do mundo subjetivo. Esses aspectos apresentam-se como: benéficos, infelizes, estranhos, etc. do ponto de vista de quem avalia. As modalizações pragmáticas são usadas para explicitar aspectos da responsabilização de uma entidade (personagem, grupo, instituição, etc.) constitutiva do conteúdo temático. Esses aspectos atribuem aos agentes (não ao produtor): intenções, razões (causa, restrições, etc), capacidades para o agir.

No nível semântico os resultados das análises dos demais níveis são reinterpretados considerando conceitos/categorias de uma semiologia do agir (MACHADO; BRONCKART, 2009; BRONCKART; MACHADO, 2004). Neste nível, as análises voltam-se a responder questões sobre o trabalho docente, baseando-se em uma síntese dos elementos semânticos ou em categorias do agir identificados pelas análises dos níveis textuais: os principais actantes colocados em cena pelo texto, as intenções, as motivações, e os recursos para o agir, os modos de agir/figuras de ação, etc.

Procuramos analisar o regulamento do PIBID com base nos conceitos apresentados acima, conforme descrevemos na próxima seção.

\section{Os procedimentos metodológicos utilizados na análise do regulamento}

Como já mencionado, para análise do regulamento, nos utilizamos do modelo de análise de textos de Bronckart (1999); Bronckart e Machado (2004); Machado e Bronckart (2009) apresentado na seção de fundamentação teórica deste artigo. Para tanto, organizamos nossas análises em três níveis procedimentais: organizacional, enunciativo e semântico. Assim, primeiramente, procuramos analisar as condições de produção do regulamento do PIBID e os textos com os quais o Regulamento estabelece intertextualidade. No nível organizacional, analisamos a organização do movimento temático do texto. Para a análise dos movimentos temáticos do Regulamento, utilizamos as categorias propostas por Bronckart (2008) e Bulea (2010) de segmentos de orientação temática (SOT), para os segmentos que indicam a introdução de tema no texto e segmentos de tratamento temático (STT), para os segmentos que indicam o desenvolvimento do tema no texto.

No nível enunciativo, observamos o uso de modalizadores e vozes. No nível semântico procuramos identificar os motivos, intenções e recursos para o agir textualizados no texto, assim como, buscamos identificar quem são os protagonistas no documento. 
Dossiê Especial: Experiências do PIBID na formação inicial e continuada de professores de

línguas estrangeiras

HIBARINO \& NODARI (orgs)

Revista X, vol.1, 2015

\section{O contexto de pesquisa: uma breve apresentação do programa PIBID}

O PIBID é um programa do Ministério da Educação (MEC) que tem como objetivo principal o aperfeiçoamento, a valorização da carreira docente e a melhoria da educação básica (CAPES, 2013). O programa promove a inserção de alunos licenciandos no cotidiano das escolas públicas desde o início da graduação, por meio de parcerias entre universidades e escolas. Para participar do PIBID, licenciandos, professores atuantes da rede pública de ensino e professores de instituições de ensino superior (IES) recebem, como incentivo, bolsas para o desenvolvimento de atividades que alinhem teoria e prática. Para fazer parte do programa, as IES que oferecem cursos de licenciatura devem submeter um projeto institucional de iniciação à docência (um projeto guarda-chuva) e subprojetos (vinculados a ele) à CAPES de acordo com as normas estabelecidas por editais e pelo regulamento do programa. Os participantes são selecionados por meio de processo seletivo promovidos pelas próprias IES.

É denominado coordenador institucional o professor de educação superior responsável por acompanhar o planejamento, a organização e o desenvolvimento das atividades propostas dentro de sua instituição. Recebe a denominação de coordenador de área de gestão de processos educacionais, o professor de educação superior, corresponsável pelo desenvolvimento das atividades do projeto institucional. É chamado coordenador de área, o professor da educação superior responsável pelo planejamento, organização e desenvolvimento das atividades previstas no subprojeto, bem como, por promover o diálogo com as escolas públicas onde os bolsistas exercem suas atividades. Recebe a denominação de professor supervisor, o docente da rede pública de ensino, responsável por supervisionar as atividades realizadas pelos bolsistas na escola. É chamado de bolsista de iniciação à docência, o aluno regularmente matriculado em curso de licenciatura participante do projeto PIBID.

Descritos os objetivos e participantes do programa PIBID, seguimos na sequência com uma descrição geral de nossos dados de análise - a descrição do Regulamento do PIBID.

\section{O Regulamento do PIBID}

O Regulamento do PIBID foi aprovado na forma dos anexos I e II da Portaria $\mathrm{n}^{\circ}$. 096, de 18 de julho de 2013. A portaria é um documento oficial da CAPES redigida em 24 páginas e está dividida em uma página inicial e dois anexos. A página inicial, composta de 
Dossiê Especial: Experiências do PIBID na formação inicial e continuada de professores de línguas estrangeiras

HIBARINO \& NODARI (orgs)

Revista X, vol.1, 2015

quatro artigos, aprova o regulamento, dispõe sobre o local de sua publicação, estabelece a data de início da vigência do documento e revoga a Portaria nº. 260, de 30 de outubro de 2010 que normatizava o programa até então. $\mathrm{O}$ anexo I do documento está dividido em 11 capítulos que dão instruções sobre a execução das atividades do PIBID. O anexo II do documento apresenta dois quadros que delimitam a quantidade de bolsas oferecidas por projeto e subprojeto.

Tendo em vista os objetivos específicos deste artigo, selecionamos para análise apenas as partes do documento que, de alguma forma, se referem aos princípios pedagógicos que norteiam o programa e/ou dão prescrições ao trabalho dos participantes. Sendo assim, as partes selecionadas para análise foram: capítulo I; seção I do capítulo II e seção V do capítulo VI (anexo I).

Apresentados nossos dados de pesquisa, passamos a seguir para a análise do contexto de produção do regulamento.

\section{O contexto de produção do regulamento do PIBID}

O regulamento do PIBID é um texto normativo cujo principal objetivo é regulamentar o funcionamento do programa, ou seja, oficializar as regras que deverão ser respeitadas por seus participantes. O documento tem como intertextos portarias e editais publicados anteriormente nas primeiras edições do programa, a Lei de Diretrizes e Bases da Educação Nacional (LDB) e o Plano Nacional de Educação (PNE). Não há indícios no documento de quem seja seu emissor (a pessoa física que produziu o texto), mas quem assina o documento oficialmente é o presidente da CAPES representando a instituição. No entanto, com base nos trâmites burocráticos recorrentes em instituições públicas brasileiras, é possível presumir que ele tenha sido elaborado por uma comissão ou conselho responsável pela regulamentação dos programas da instituição. Os receptores (pessoas físicas às quais o texto é destinado) são, entre outros, professores do ensino superior e da rede pública, alunos, reitores, coordenadores, diretores das IES ou de escolas que participam ou tenham interesse em participar do programa ou que tenham interesse em manter ou inserir sua instituição nele.

Como enunciador (papel social assumido pelo emissor), temos o presidente da CAPES enquanto autoridade maior que representa a instituição, órgão do MEC e, como destinatários (papéis sociais assumidos pelos receptores dos textos), os candidatos e/ou participantes do programa. No que se refere à situação de produção do documento, o texto não nos possibilita informações concretas sobre seu contexto físico (lugar de produção), 
Dossiê Especial: Experiências do PIBID na formação inicial e continuada de professores de línguas estrangeiras

HIBARINO \& NODARI (orgs)

Revista X, vol.1, 2015

mas nos é possível inferir que ele tenha sido produzido nas dependências da CAPES. Quanto aos objetivos de comunicação do documento, ele visa estabelecer regras para o funcionamento do programa, bem como subsidiar a elaboração dos editais de seleção. $\mathrm{O}$ suporte no qual o regulamento foi publicado e está disponível para consulta é a página eletrônica da $\mathrm{CAPES}^{10}$, provavelmente por ser um espaço que permite ampla divulgação entre seus destinatários.

A seguir, aprofundamos nossos olhares nos capítulo e seções do regulamento selecionadas para análise.

\section{Análise do Regulamento do PIBID nos níveis organizacional, enunciativo e semântico}

O primeiro capítulo do regulamento traz a definição do programa e seus objetivos, o que é esperado por tratar-se do capítulo introdutório. Deste modo, os SOT identificados em nossa análise foram "definição do PIBID" e "Objetivos do PIBID". Os STT desenvolvidos pelo primeiro SOT foram: a finalidade, as contribuições visadas e os envolvidos no programa, conforme apresentamos no quadro I:

Quadro 1 - SOT e STT identificados no capítulo I do Regulamento

\begin{tabular}{|l|l|}
\hline $\begin{array}{c}\text { SEGMENTO DE ORIENTAÇÃO } \\
\text { TEMÁTICA (SOT) }\end{array}$ & \multicolumn{1}{|c|}{$\begin{array}{c}\text { SEGMENTO DE TRATAMENTO TEMÁTICO } \\
\text { (STT) }\end{array}$} \\
\hline \multirow{5}{*}{ Definição do PIBID } & $\begin{array}{l}\text { Finalidade do programa; } \\
\text { Contribuições visadas; } \\
\text { Envolvidos no programa. }\end{array}$ \\
\hline & $\begin{array}{l}\text { Incentivo à formação docente; } \\
\text { Valorização do magistério; }\end{array}$ \\
& $\begin{array}{l}\text { Elevação da qualidade da formação inicial; } \\
\text { Integração da educação superior e educação básica; }\end{array}$ \\
& $\begin{array}{l}\text { Inserção dos licenciandos no cotidiano das escolas } \\
\text { públicas; } \\
\text { Mobilização dos professores das escolas públicas como } \\
\text { co-formadores da formação inicial; }\end{array}$ \\
& $\begin{array}{l}\text { Articulação teoria e prática; } \\
\text { Apropriação e reflexão sobre os instrumentos e saberes } \\
\text { do trabalho docente. }\end{array}$ \\
\hline
\end{tabular}

A sequência e a maneira como são desenvolvidos os STT nos passa a impressão de que o documento apresenta uma problemática, uma proposta de intervenção e a definição dos envolvidos nela. A problemática nesse contexto seria a baixa qualidade da

\footnotetext{
${ }^{10}$ O Regulamento do PIBID pode ser encontrado no site: http://www.capes.gov.br/educacao-basica/capespibid.
} 
Dossiê Especial: Experiências do PIBID na formação inicial e continuada de professores de

línguas estrangeiras

HIBARINO \& NODARI (orgs)

Revista X, vol.1, 2015

educação básica e dos cursos de licenciaturas que necessitam da intervenção de programas como o PIBID, e os agentes de transformação dessa realidade seriam os professores de ensino superior, os professores da escola pública e os próprios licenciandos. Dessa forma, é possível concluir que o regulamento revela o PIBID enquanto um programa que intenciona intervir diretamente nos diferentes níveis de educação, por meio de uma nova proposta de formação inicial e continuada de professores.

Neste capítulo, não é possível identificar a presença de modalizadores, o que, a nosso ver, é característica do gênero textual regulamento, um documento normativo que visa estabelecer as regras de determinada atividade. Acreditamos, dessa forma que a ausência de modalizações, se constitui, nesse caso, como uma forma própria de modalizar o texto; em outras palavras, a ausência de modalizadores é utilizada para construir um discurso impositivo, que não deixe outra alternativa aos participantes senão seguir as normas estabelecidas. O texto apresenta uma série de verbos no infinitivo (fomentar, incentivar, contribuir, elevar, inserir) procurando persuadir o leitor de que os propósitos do programa serão certamente alcançados.

Em relação ao SOT “objetivos do PIBID”, os STT identificados fazem menção à necessidade de incentivo à formação docente, à valorização do magistério e à elevação da qualidade na formação inicial. Deste modo é possível entender que o programa se apresenta como instrumento de reação às contínuas transformações sócio-históricas que vêm ocorrendo nas relações de trabalho da profissão docente no Brasil, na qual nos deparamos com o crescente desprestígio da profissão e o consequente desinteresse pelas vagas de cursos de licenciatura. Os cursos de licenciaturas são colocados como alvo de intervenção, área da educação que precisa ser melhorada, ou seja, que não está correspondendo às exigências sociais contemporâneas. Assim, identificamos a necessidade de melhorar a qualidade dos cursos de licenciaturas e da educação básica como motivações para o agir, reveladas pelo texto; ou seja, tal necessidade aparece como determinante externo (exigências sociais) para o agir no contexto do PIBID.

Os STT - integração da educação superior com a educação básica, inserção dos licenciandos no cotidiano das escolas públicas, mobilização dos professores das escolas públicas como co-formadores da formação inicial, articulação teoria e prática; apropriação e reflexão sobre os instrumentos e saberes do trabalho docente - aparecem como as formas de intervenção utilizadas no combate ao problema, ou seja, os recursos para o agir. Assim, podemos inferir que a vivência continua dos licenciandos nas escolas públicas e; as 
Dossiê Especial: Experiências do PIBID na formação inicial e continuada de professores de línguas estrangeiras

HIBARINO \& NODARI (orgs)

Revista X, vol.1, 2015

possibilidades de estabelecimento de relações entre teoria e prática aparecem como mola mestra do programa, capaz de contribuir com o aumento da qualidade da educação. É possível afirmar que o programa sustenta a premissa de que a universidade e a escola devem unir forças em prol da formação docente. Torna-se importante observar ainda que as práticas propostas pelo programa convidam as escolas públicas a assumir o papel de protagonistas da formação inicial, mobilizando os professores como co-formadores desse processo (MATEUS; EL KADRI; GAFFURI, 2011). Ação essa que, possivelmente, aparece na tentativa de transformar as relações entre a universidade e a escola, nas quais o professor, muitas vezes, apenas cedia suas aulas para intervenção dos alunos - professores em formação inicial, sem um maior engajamento com sua formação.

O capítulo II, na seção que selecionamos para análise, detalha o que o projeto institucional deve abordar quanto às características e dimensões da iniciação à docência, bem como estabelece a maneira como se deve dar a articulação entre a IES e o sistema público de educação. Considerando os objetivos do capítulo, é possível afirmar que nele o regulamento estabelece qual formação o programa pretende oferecer para o aluno-professor. Organizamos os SOT e STT mobilizados no texto no quadro a seguir:

Quadro 2 - SOT e STT identificados na seção I do capítulo II do Regulamento

\begin{tabular}{|l|l|}
\begin{tabular}{|l} 
SEGMENTO DE ORIENTAÇÃO \\
TEMÁTICA (SOT)
\end{tabular} & \multicolumn{1}{|c|}{$\begin{array}{c}\text { SEGMENTO DE TRATAMENTO TEMÁTICO } \\
\text { (STT) }\end{array}$} \\
\hline \multirow{5}{*}{$\begin{array}{l}\text { Características e dimensões da } \\
\text { iniciação à docência }\end{array}$} & $\begin{array}{l}\text { Estudo do contexto educacional; } \\
\text { Desenvolvimento de ações de valorização ao trabalho } \\
\text { coletivo; } \\
\text { Planejamento e execução de atividades na escola e na } \\
\text { IES; }\end{array}$ \\
& $\begin{array}{l}\text { Participação nas atividades de planejamento do PPP da } \\
\text { escola; }\end{array}$ \\
& $\begin{array}{l}\text { Participação em reuniões pedagógicas na escola; } \\
\text { Análise do processo de ensino-aprendizagem; } \\
\text { Análise das diretrizes e currículos da educação básica; }\end{array}$ \\
& $\begin{array}{l}\text { Leitura e discussão de referenciais teóricos } \\
\text { contemporâneos; } \\
\text { Desenvolvimento e aplicação de estratégias didático- } \\
\text { pedagógicas; } \\
\text { Desenvolvimento de ações articuladas entre os } \\
\text { membros do programa e a comunidade escolar; }\end{array}$ \\
& $\begin{array}{l}\text { Sistematização e registro das atividades desenvolvidas } \\
\text { em portfólio. }\end{array}$ \\
\hline & $\begin{array}{l}\text { Inserção dos licenciandos nas escolas públicas; } \\
\text { Socialização dos impactos e resultados do programa; }\end{array}$ \\
\hline
\end{tabular}


Dossiê Especial: Experiências do PIBID na formação inicial e continuada de professores de

línguas estrangeiras

HIBARINO \& NODARI (orgs)

Revista X, vol.1, 2015

Articulação entre a IES e o sistema público de educação básica

Ampliação e aperfeiçoamento do uso da língua portuguesa;

Transversalidade das questões socioambientais, éticas e da diversidade nas propostas de todos os subprojetos;

Recomendações sobre a seleção das escolas participantes do programa.

$\mathrm{Na}$ seção analisada, identificamos dois SOT: "características e dimensões da iniciação à docência" e "articulação entre a IES e o sistema público de educação básica". Os STT identificados em relação às caraterísticas e dimensões da iniciação à docência que o projeto institucional deve contemplar incluem: estudo do contexto educacional, desenvolvimento de trabalho coletivo entre os participantes do projeto e os membros da comunidade escolar, leitura de documentos prescritivos do trabalho docente, análise dos processos de ensino e aprendizagem, entre outros. É possível notar assim que, na proposta de formação do programa, os sujeitos são vistos como profissionais capazes de realizar análises que envolvem diferentes momentos do trabalho docente e dos processos de ensino e aprendizagem a fim de estabelecer mudanças no contexto de atuação. Os participantes são vistos como capazes de transformar as ações rotinizadas no contexto escolar. A forma de avaliação proposta pelo programa é a elaboração de portfólios, embora o documento não explicite as razões da escolha deste instrumento. A elaboração de portfólios é um instrumento que possibilita a autorregulação dos processos de ensino e aprendizagem, podendo contribuir para o desenvolvimento da autonomia dos bolsistas.

É possível afirmar; deste modo que, a proposta de formação do programa PIBID alinha-se às propostas contemporâneas de formação. Propostas críticas e crítico-reflexivas (LIBERALI, 2008; MAGALHÃES, 2004; CELANI, 2002) voltadas à formação de profissionais críticos e autônomos, que propiciem a compreensão de aspectos sociais, culturais e políticos que envolvem o trabalho docente, como podemos perceber pela valorização do estudo do contexto educacional, pelo foco no trabalho coletivo em detrimento da visão individualizada do trabalho docente cristalizada pelas abordagens tradicional e tecnicista. É possível concluir ainda que o programa se baseia em projetos de formação docente contemporâneos que defendem o fortalecimento de parcerias entre a universidade e a escola como possibilidades significativas de formação (CRISTOVÃO, 2011; MATEUS, 2009; FURTOSO, ET AL, 2009; GIMENEZ; PEREIRA, 2007).

Com relação à análise das vozes presentes no texto, observamos nessa seção, como também em todas as partes do documento analisadas, a presença de uma única voz, 
Dossiê Especial: Experiências do PIBID na formação inicial e continuada de professores de línguas estrangeiras

HIBARINO \& NODARI (orgs)

Revista X, vol.1, 2015

a voz institucional da CAPES, podendo ser classificada conforme a categorização proposta por Bronckart (1999) como voz social, procedente de instituições sociais, no caso a CAPES. A instituição assume a responsabilização por tudo que é dito marcando assim o distanciamento do enunciador para com seus enunciatários e lhe conferindo autoridade sobre eles. Não aparece no texto a voz dos demais envolvidos no programa, de outras instituições sociais ou de teóricos da educação.

Sendo assim, é possível perceber de forma clara a demarcação hierárquica entre a CAPES (MEC) para com as demais instituições envolvidas, ou seja, a CAPES enquanto órgão institucional do MEC tem poder de apontar aquilo que deve ser feito pelos professores das IES da rede básica de ensino. Isto nos é mostrado também pela predominância de modalizações deônticas encontradas nessa seção, como vemos nos excertos abaixo:

Art. $5^{\circ} \mathrm{O}$ projeto Pibid tem caráter institucional, portanto, cada instituição de ensino superior (IES) poderá possuir apenas um projeto em andamento.

Art. $6^{\circ} \mathrm{O}$ projeto institucional deve abranger diferentes características e dimensões da iniciação à docência, entre as quais: [...] (p. 03).

No primeiro fragmento, o uso da modalização pelo verbo auxiliar poderá em conjunto com a palavra apenas, indica que, se o projeto da IES não se adequar as normas do regulamento, a IES não poderá fazer parte do programa. De acordo com as funções das modalizações propostas por Bronckart (1999), a modalização poderá seria classificada como modalização lógica. No entanto, em conjunto com o advérbio de exclusão apenas, entendemos que ela assume função deôntica no texto, já que pode ser substituída por deverá sem a alteração do sentido da frase, excluindo assim, a alternativa das IES de não seguir esta norma do regulamento. O mesmo acontece no $\S 2^{\circ}$ do art. $9^{\circ}$; nesse caso, a modalização é usada para estabelecer a regra de que o projeto institucional deve apresentar apenas um subprojeto por licenciatura em cada campus, bem como garantir que seja respeitado o número mínimo e máximo de alunos bolsistas por subprojeto estabelecido pelo regulamento.

No segundo fragmento, a presença da modalização deôntica deve; é utilizada uma única vez, com o fim de modalizar os onze itens do art. $6^{\circ}$, que estabelece as características e dimensões da iniciação à docência que o projeto institucional deve abranger. A expressão entre as quais e a presença do recurso de pontuação "dois pontos" estabelece deve como modalizador para todos os itens que seguem, marcando a presença recorrente da modalização deôntica no texto, usada para excluir do programa outras propostas de formação docente que 
Dossiê Especial: Experiências do PIBID na formação inicial e continuada de professores de línguas estrangeiras

HIBARINO \& NODARI (orgs)

Revista X, vol.1, 2015

não a estabelecida pelo regulamento. Identificamos no texto, também, a presença da modalização deôntica deve utilizada para modalizar os cinco itens do art. $7^{\circ}$, utilizada para estabelecer como se deve dar a articulação entre a universidade e a escola.

Como podemos observar pelos STT desenvolvidos no SOT "articulação entre a IES e o sistema público de educação básica", o documento ressalta a necessidade de inserção dos licenciandos no contexto das escolas públicas, explicita a necessidade de socialização dos impactos e resultados alcançados pelo programa, e prescreve a transversalidade de questões socioambientais, éticas e da diversidade nas propostas de todos os subprojetos, além de prescrever o aperfeiçoamento do uso da língua portuguesa. Este último STT é enfatizado também em outras partes do documento, revelando o uso formal da língua portuguesa como aspecto frágil da educação no país.

Identificamos nesta seção; também a presença das modalizações lógicas recomendável e poderão, usadas para indicar certa abertura quanto à escolha das escolas participantes do programa e quanto à possibilidade de submissão de projetos interdisciplinares. Acreditamos que tal abertura é dada para evitar possíveis problemas na viabilização do programa. O regulamento recomenda que as IES desenvolvam as atividades do programa em escolas com IDEB abaixo da média nacional e também nas escolas que apresentem "experiências bem sucedidas de ensino e aprendizagem" (item I do art. $8^{\circ}$ ), para que seja possível alcançar diferentes realidades e necessidades da educação básica. Considerando que as escolas têm autonomia de aceitar ou não participar do programa, pode acontecer das IES não conseguirem cumprir com tal critério, fator que a nosso ver justifica a abertura dada pelo regulamento.

Pode-se observar que o regulamento procura estabelecer as médias do IDEB como critério (recomendável) norteador das intervenções do programa, e que entende que as escolas que apresentam IDEB abaixo da média; não possuem "experiências bem sucedidas de aprendizagem", discurso este que desconsidera os diferentes contextos sociais em que as escolas estão inseridas, os diferentes aspectos dos fatores sociais e econômicos que interferem nos processos de ensino e aprendizagem e coloca sobre a escola e seus professores a responsabilidade pelas baixas médias no IDEB.

Quanto à abertura dada a apresentação de projetos interdisciplinares, acreditamos que ela seja justificada pelo fato de que projetos como esses ainda se constituem como desafios para a educação brasileira. 
Dossiê Especial: Experiências do PIBID na formação inicial e continuada de professores de línguas estrangeiras

HIBARINO \& NODARI (orgs)

Revista X, vol.1, 2015

A seção V do capítulo VI selecionada para nossas análises estabelece os deveres dos participantes do programa. Por essa razão, procuramos voltar nossas análises para o trabalho prescrito aos envolvidos no PIBID. Nessa seção, assim como no capítulo I, não foi possível identificar a presença de modalizações e, como já mencionado, acreditamos que a ausência de modalizadores é um recurso utilizado para explicitar as coerções impostas pelo regulamento aos participantes, apresentando-os a única opção de seguir as normas do regulamento. Observamos, no entanto, a utilização recorrente de verbos ${ }^{11}$ no infinitivo (responder, acompanhar, acordar, empreender, comunicar, elaborar, articular, garantir, realizar, participar, utilizar, apoiar, colaborar, etc.) utilizados para detalhar o trabalho prescrito a cada participante do programa.

Os SOT identificados na seção introduzem o trabalho prescrito a cada participante do programa. A partir deles, pudemos identificar em nossas análises dois tipos principais de STT, os que se relacionam à prescrição do trabalho burocrático a ser cumprido pelos bolsistas e os que se relacionam ao trabalho pedagógico desenvolvido na IES e na escola. Como podemos observar no quadro 3:

Quadro 3 - SOT e STT identificados na seção V do capítulo VI do Regulamento

\begin{tabular}{|l|l|}
\hline $\begin{array}{l}\text { SEGMENTO DE ORIENTAÇÃO } \\
\text { TEMÁTICA (SOT) }\end{array}$ & \multicolumn{1}{|c|}{$\begin{array}{c}\text { SEGMENTO DE TRATAMENTO TEMÁTICO } \\
\text { (STT) }\end{array}$} \\
\hline \multirow{5}{*}{$\begin{array}{l}\text { Deveres do Coordenador } \\
\text { Institucional }\end{array}$} & $\begin{array}{l}\text { Coordenação geral do programa perante às escolas, à } \\
\text { IES, às secretarias de educação e à CAPES; } \\
\text { Acompanhamento das atividades previstas no projeto e } \\
\text { subprojetos; } \\
\text { Articulação com as autoridades da rede pública; } \\
\text { Uso do português de acordo com a norma culta quando } \\
\text { tratar-se de comunicação oficial do programa; } \\
\text { Realização da seleção dos coordenadores de área; } \\
\text { Elaboração encaminhamento de relatório das } \\
\text { atividades desenvolvidas no projeto; } \\
\text { Articulação de possibilidades de trabalho } \\
\text { interdisciplinar nas escolas participantes do programa; } \\
\text { Cadastramento e atualização dos dados dos bolsistas } \\
\text { junto a CAPES; } \\
\text { Acompanhamento do pagamento das bolsas; } \\
\text { Manutenção da guarda institucional dos documentos do } \\
\text { projeto; }\end{array}$ \\
\hline
\end{tabular}

\footnotetext{
${ }^{11}$ Devido às limitações de espaço para este artigo, não pudemos realizar a análise dos verbos presentes no texto; acreditamos que estas análises poderiam nos oferecer uma visão mais completa das prescrições textualizadas no regulamento.
} 
Dossiê Especial: Experiências do PIBID na formação inicial e continuada de professores de

línguas estrangeiras

HIBARINO \& NODARI (orgs)

Revista X, vol.1, 2015

\begin{tabular}{|c|c|}
\hline & $\begin{array}{l}\text { Promoção de reunião e encontros entre os bolsistas; } \\
\text { Participação nas atividades de acompanhamento e } \\
\text { avaliação do PIBID; } \\
\text { Prestação de conta técnica e financeira nos prazos } \\
\text { estabelecidos; } \\
\text { Manutenção dos dados da plataforma lattes atualizados; } \\
\text { Compartilhamento das boas práticas do PIBID. }\end{array}$ \\
\hline $\begin{array}{l}\text { Deveres do coordenador de área de } \\
\text { gestação de processos educacionais }\end{array}$ & $\begin{array}{l}\text { Apoio ao coordenador institucional; } \\
\text { Colaboração na articulação institucional das atividades } \\
\text { do programa; } \\
\text { Promoção de reunião periódicas com a equipe do } \\
\text { programa; } \\
\text { Representação do coordenador institucional quando } \\
\text { necessário; } \\
\text { Elaboração de relatórios de gestão; } \\
\text { Uso do português de acordo com a norma culta quando } \\
\text { tratar-se de comunicação oficial do programa; } \\
\text { Participação nas atividades de acompanhamento e } \\
\text { avaliação do PIBID; } \\
\text { Manutenção dos dados da plataforma lattes atualizados; } \\
\text { Compartilhamento das boas práticas do PIBID. }\end{array}$ \\
\hline Deveres do Coordenador de área & $\begin{array}{l}\text { Coordenação do subprojeto; } \\
\text { Elaboração, desenvolvimento e acompanhamento das } \\
\text { atividades previstas no subprojeto; } \\
\text { Participação nas comissões de seleção de bolsistas de } \\
\text { iniciação à docência e supervisores; } \\
\text { Orientação da atuação dos bolsistas em conjunto com } \\
\text { os supervisores; } \\
\text { Elaboração de relatórios periódicos com a descrição, } \\
\text { avaliação e análise das atividades do subprojeto; } \\
\text { Uso do português de acordo com a norma culta quando } \\
\text { tratar-se de comunicação oficial do programa; } \\
\text { Participação em seminários de iniciação à docência } \\
\text { promovido pela IES; } \\
\text { Participação nas atividades de acompanhamento e } \\
\text { avaliação do PIBID; } \\
\text { Manutenção dos dados da plataforma lattes atualizados; } \\
\text { Compartilhamento das boas práticas do PIBID; } \\
\text { Elaboração e desenvolvimento de projetos } \\
\text { interdisciplinares. }\end{array}$ \\
\hline Deveres do Supervisor & $\begin{array}{l}\text { Elaboração, desenvolvimento e acompanhamento das } \\
\text { atividades dos bolsistas de iniciação à docência; } \\
\text { Controle da frequência dos bolsistas de iniciação à } \\
\text { docência na escola; } \\
\text { Uso do português de acordo com a norma culta quando } \\
\text { tratar-se de comunicação oficial do programa; } \\
\text { Participação em seminários de iniciação à docência } \\
\text { promovido pela IES; } \\
\text { Divulgação das atividades do projeto junto à }\end{array}$ \\
\hline
\end{tabular}




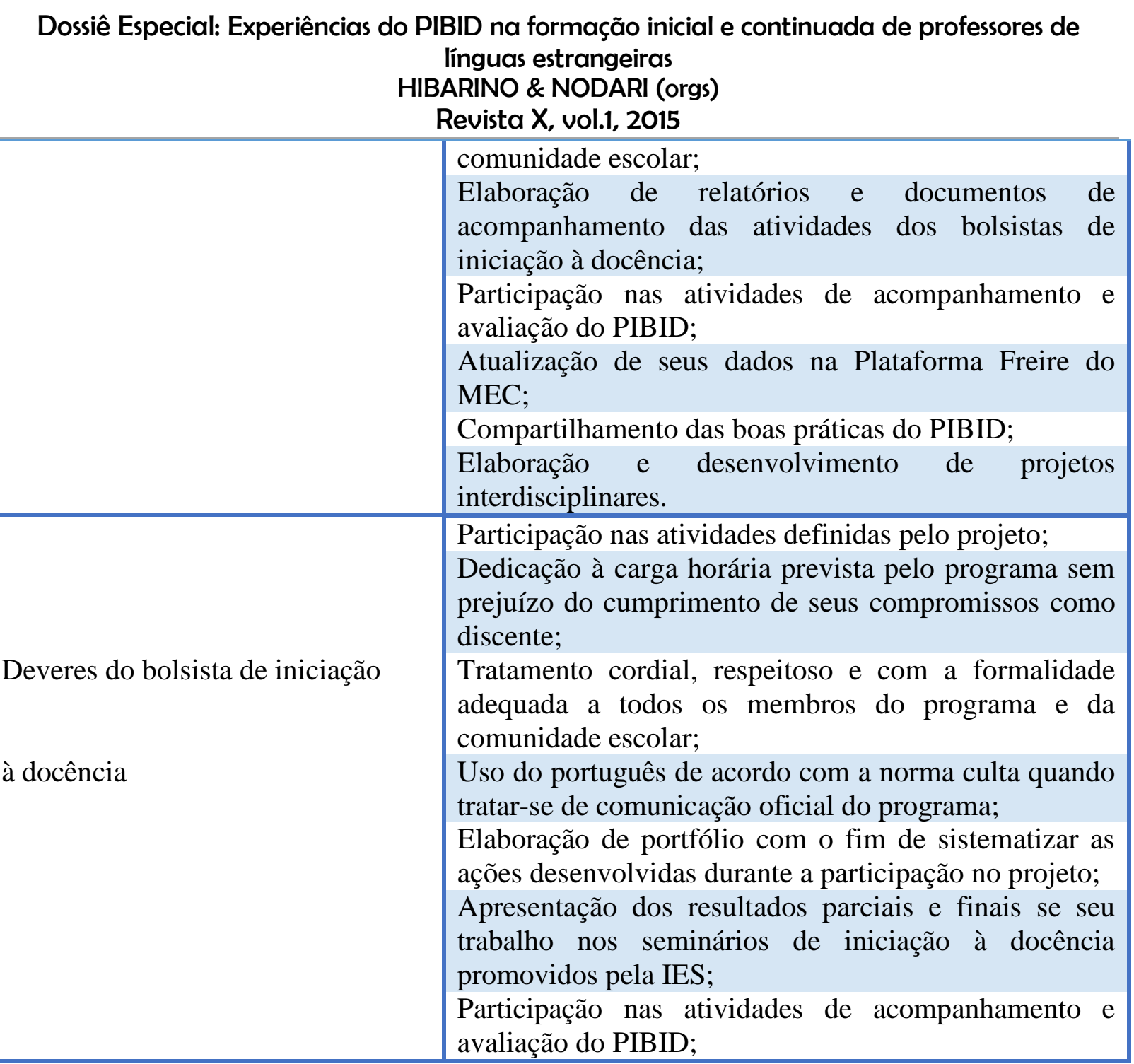

Observamos em nossas análises que a maior parte das prescrições direcionadas ao trabalho do coordenador institucional é de ordem burocrática, sendo grande parte delas voltadas à elaboração de instrumentos para a avaliação e controle das atividades do programa pela CAPES, e parte delas voltadas às ações que possibilitem o bom andamento das atividades do programa. Quanto ao que se refere ao desenvolvimento do trabalho pedagógico, percebemos com esse levantamento que o documento prescreve a este profissional um olhar amplo sobre as atividades realizadas pelo projeto, uma vez que ele deverá acompanhar o desenvolvimento das atividades realizadas por todos os subprojetos e ainda assumir o compromisso de articulação entre os membros do programa visando possibilidades de ações interdisciplinares.

Quanto ao SOT “deveres do coordenador de área de gestação de processos educacionais" identificamos STT muito próximos aos identificados para o SOT “deveres do coordenador institucional”, o que já era esperado, uma vez que este profissional dá apoio ao 
Dossiê Especial: Experiências do PIBID na formação inicial e continuada de professores de

línguas estrangeiras

HIBARINO \& NODARI (orgs)

Revista X, vol.1, 2015

trabalho realizado pelo coordenador institucional. Podemos notar, no entanto, certa diminuição ou quase apagamento do trabalho pedagógico prescrito a esse participante.

Com relação ao SOT “deveres do coordenador de área”, é possível perceber que o trabalho prescrito ao professor engloba diferentes aspectos do trabalho docente, do planejamento, elaboração e execução das atividades do subprojeto a sua avaliação, corroborando a asserção de Machado (2007, p. 93) de que

[...] o trabalho docente, resumidamente, consiste em uma mobilização, pelo professor, de seu ser integral, em diferentes situações - de planejamento, de aula, de avaliação, com o objetivo de criar um meio que possibilite aos alunos a aprendizagem de um conjunto de conteúdos de sua disciplina e o desenvolvimento de capacidades específicas relacionadas a esses conteúdos.

No que se refere ao SOT “deveres do supervisor”, as prescrições dadas ao professor supervisor, similares àquelas dadas ao professor coordenador, incluem o planejamento, a elaboração, a execução e a avaliação das atividades do subprojeto. É possível inferir que o professor da educação básica deverá ter conhecimentos/habilidades de lidar com os problemas do dia-a-dia à luz das discussões teóricas e práticas realizadas conjuntamente com os demais participantes do programa.

O último SOT identificado em nossas análises foi “deveres do bolsista de iniciação à docência”. Observando os STT relacionados a esse SOT, é possível notar que o trabalho burocrático dos alunos-bolsistas é prescrito pelo regulamento, já o trabalho pedagógico depende da proposta do subprojeto, revelando a prescrição dada a estes participantes como uma prescrição genérica. A partir de nossas análises e considerando que os planos dos projetos e subprojetos das IES apresentam propostas de trabalho ancorados em concepções formativas e pressupostos teórico-metodológicos diversos, é possível afirmar que as experiências vivenciadas pelos alunos-bolsistas no programa do PIBID podem tomar sentidos diferenciados a depender do contexto de atuação dos participantes e da proposta de trabalho defendida/oferecida pela IES.

\section{Considerações finais}

Neste artigo, procuramos analisar o Regulamento do programa PIBID, a fim de identificar que concepção(es) formativa(s) e que prescrições ao trabalho docente são textualizadas no documento. Para tanto, procuramos responder a seguintes perguntas: a) que 
Dossiê Especial: Experiências do PIBID na formação inicial e continuada de professores de línguas estrangeiras

HIBARINO \& NODARI (orgs)

Revista X, vol.1, 2015

concepção(es) formativa(s) norteia(m) o PIBID? b) quem são os protagonistas no regulamento do programa? c) qual o trabalho prescrito aos participantes do programa?

Nossas análises nos permitiram concluir que o programa prescreve a seus participantes uma formação alinhada às concepções teóricas contemporâneas de formação crítica e crítico reflexiva voltadas à compreensão dos aspectos sociais, culturais e políticos que envolvem o trabalho do professor. Também se alinha às propostas de formação que visam ao fortalecimento dos laços entre a universidade e a escola, possibilitando condições contextuais que integrem teoria e prática. $\mathrm{O}$ documento apresenta como protagonistas dessa formação os professores das IES, os professores das escolas públicas e os próprios alunosprofessores participantes do programa, como atores transformadores da prática docente. $\mathrm{O}$ trabalho prescrito ao professor coordenador institucional e ao professor coordenador de área de gestação de processos educacionais é em sua maioria de cunho burocrático. As prescrições dadas ao professor coordenador de área e ao professor supervisor procura abarcar diferentes aspectos do trabalho docente, estendendo-se do planejamento à avaliação das atividades desenvolvidas. O trabalho prescrito ao aluno-bolsista é genérico e depende das atividades propostas pelo projeto e subprojeto.

Um olhar geral sobre as análises realizadas aponta para a importância de se pensar cuidadosamente o plano dos projetos e subprojetos de cada IES, uma vez que, a mola mestra do programa, a articulação entre teoria de prática, é dependente da maneira como são pensadas e conduzidas as atividades de cada proposta.

\section{Agradecimento}

Agradeço à CAPES pela concessão da bolsa PIBID que possibilitou a realização desta pesquisa.

\section{Referências}

AMIGUES, R. "Trabalho do professor e trabalho de ensino". IN: MACHADO, A. R. (Org.) O ensino como trabalho: uma abordagem discursiva. Londrina: EDUEL, 2004, Pp. 35-53.

BRASIL, MEC. Parâmetros Curriculares Nacionais. Brasília: Ministério da Educação e do Desporto, Secretaria de Educação Fundamental, 1998.

BRONCKART, J. P. Atividade de linguagem, textos e discursos: por um interacionismo sócio-discursivo. Trad. de A. R. Machado e P. Cunha. São Paulo: Educ, 1999.

O agir nos discursos: das concepções teóricas às concepções dos trabalhadores. Campinas: Mercado de Letras, 2008. 
Dossiê Especial: Experiências do PIBID na formação inicial e continuada de professores de

línguas estrangeiras

HIBARINO \& NODARI (orgs)

Revista X, vol.1, 2015

BRONCKART, J. P.; MACHADO, A. R. "Procedimentos de análise de textos sobre o trabalho educacional". IN: MACHADO, A. R. (Org.) O ensino como trabalho: uma abordagem discursiva. Londrina: Eduel, 2004, Pp. 131-163.

BUENO, L. A construção de representações sobre o trabalho docente: o papel do estágio. 2007. 205 f. Tese (Doutorado em Linguística Aplicada e Estudos da Linguagem) - Pontifícia Universidade Católica de São Paulo, São Paulo.

BULEA, E. Linguagem e efeitos desenvolvimentais da interpretação da atividade. Campinas: Mercado de Letras, 2010.

CAPES. Regulamento do Programa Institucional de Iniciação à Docência. PIBID. 2013. IN: Portaria $\mathrm{n}^{\mathrm{o}}$ 096, de 18 de julho de 2013. Disponível em: < http://www.capes.gov.br/educacao-basica/capespibid>. Acesso em 15 jan. 2014.

CELANI, M. A. A. A. (Org.) Professores e formadores em mudança: relato de um processo de reflexão e transformação da prática docente. Campinas: Mercado de Letras, 2002.

CLOT, Y. A função psicológica do trabalho. Rio de Janeiro: Ed. Vozes, 2006.

CRISTOVÃO, V. L. L. "Parcerias no desenvolvimento profissional do professor: espaços de (re)significação para o Estágio Supervisionado". IN: GONÇALVES, A. V.; PINHEIRO, A. S.; FERRO, M. E. (Orgs.). Estágio supervisionado e práticas educativas: diálogos interdisciplinares. Dourados: Editora UEMS, 2011. v. 1, PN, Pp.145-156.

FAITA, D. "Gêneros de discurso, gêneros de atividade, análise da atividade do professor". IN: MACHADO, A. R. (Org.) O ensino como trabalho: uma abordagem discursiva. Londrina: EDUEL, 2004, Pp. 55-80.

FURTOSO, V. B. et al. "Parceria universidade; escolas: conquistas e desafios na formação de professores". IN: MATEUS, E.; QUEVEDO-CAMARGO, G; GIMENEZ, T. (Org.). Ressignificações na formação de professores: rupturas e continuidades. Londrina: EDUEL, 2009, Pp. 45-60.

GIMENEZ, T.; PEREIRA, F. M. "Relação universidade/escola na formação de professores de inglês: primeiras aproximações". IN: GIMENEZ, T. (Org.). Tecendo as manhãs: pesquisa participativa e formação de professores de Inglês. Londrina: Fundação Araucária, 2007, Pp. 97-111.

LEITE, M. D. As diferentes facetas do trabalho do professor: dos órgãos governamentais à palavra do trabalho. 2009. 212 f. Dissertação (Linguística Aplicada e Estudos da Linguagem) - Pontifícia Universidade Católica de São Paulo, São Paulo, 2009.

LIBERALI, F. C. Formação crítica de educadores: questões fundamentais. Taubaté, São Paulo: Cabral Editora e Livraria Universitária, 2008.

MACHADO, A. R; "Por uma concepção ampliada do trabalho do professor". IN: GUIMARÃES, A. M. M.; MACHADO, A. R.; COUTINHO, M. A. (Org.). O interacionismo sociodiscursivo: questões epistemológicas e metodológicas. Campinas: Mercado de Letras, 2007, Pp. 77-97.

MACHADO, A. R; BRONCKART, J. P. "De que modo os textos oficiais prescrevem o trabalho do professor? Análise comparativa de documentos brasileiros e genebrinos". IN: DELTA: Documentação de Estudos em Linguística Teórica e Aplicada. $n^{\circ} .21,2005$, Pp.183-214. 
Dossiê Especial: Experiências do PIBID na formação inicial e continuada de professores de línguas estrangeiras

HIBARINO \& NODARI (orgs)

Revista X, vol.1, 2015

"(Re-)Configurações do trabalho do professor construídas nos e pelos textos: a perspectiva metodológica do grupo ALTER-LAEL". IN: MACHADO, A. R.; ABREUTARDELLI, L. S.; CRISTOVÃ̃, V. L. L. (Org.). Linguagem e educação: o trabalho do professor em uma nova perspectiva. Campinas, SP: Mercado de Letras, 2009, Pp. 31-77.

MACHADO, A. R; CRISTOVÃO, V. L. L. "Representações sobre o professor e seu trabalho em proposta institucional brasileira para a formação docente". IN: MACHADO, A. R.; ABREU-TARDELli, L. S.; CRISTOVÃO, V. L. L. (Org.) Linguagem e educação: o trabalho do professor em uma nova perspectiva. Campinas, SP: Mercado de Letras, 2009, Pp. 117-136.

MACHADO, A. R; LOUSADA, E.; BARADI, G.; TARDELLI, L. S. A.; TOGNATO, M. I. R. "Relações entre linguagem e trabalho educacional: novas perspectivas e métodos no quadro do interacionismo sociodiscursivo". IN: MACHADO, A. R.; ABREU-TARDELLI, L. S.; CRISTOVÃO, V. L. L. (Org.) Linguagem e educação: o trabalho do professor em uma nova perspectiva. Campinas, SP: Mercado de Letras, 2009, Pp. 15-29.

MAGALHÃES, M. C. C. "A linguagem na formação de professores como profissionais reflexivos e críticos". IN: Magalhães, M. C. C. (Org.) A formação do professor como um profissional crítico. São Paulo: Mercado de Letras, 2004, Pp. 59-85.

MATEUS, E. "Em busca de outros modos de com-viver". IN: MATEUS, E; QUEVEDOCAMARGO, G.; GIMENEZ, T. (Org.). Ressignificações na formação de professores: rupturas e continuidades. Londrina: Eduel, 2009, Pp. 61-80.

MATEUS, E.; EL KADRI, M. S.; GAFFURI, P. "O que se pode ver da janela: uma análise do subprojeto de Letras-Inglês no programa PIBID”. Signum: Estudos da Linguagem, Londrina, v. 14, 2011, Pp. 363-386.

PARANÁ, SEED. Diretrizes Curriculares de Língua Estrangeira para o Ensino Fundamental. Secretaria de Estado da Educação do Paraná, Superintendência da Educação, 2006.

REGISTRO, E. S. R.; STUTZ, L. "Textos prescritivos e o trabalho do professor no curso de Letras”. IN: CRISTOVÃO, V. L. L. (Org.). Estudos da Linguagem à luz do Interacionismo Sociodiscursivo. Londrina: UEL, 2008, Pp. 163-177.

SAUJAT, F. "O trabalho do professor nas pesquisas em educação: um panorama". IN: MACHADO, A. R (Org.). O ensino como trabalho: uma abordagem discursiva. Londrina: EDUEL, 2004, Pp. 3-34. 